\title{
MEASURING PERFORMANCE OF INVASIVE PLANT ERADICATION EFFORTS IN NEW ZEALAND
}

\author{
P. HOLLORAN
}

\begin{abstract}
Environmental Studies Department, University of California at Santa Cruz, 1156 High Street, Santa Cruz, CA 95064, USA
\end{abstract}

\section{Corresponding author: peteh@ucsc.edu}

\begin{abstract}
New Zealand's Biosecurity Act 1993, which has enabled local governments to pursue eradication of 69 different invasive plant taxa, is strongly influenced by "new public management" doctrine and its emphasis on specific management objectives, annual plans and performance measures. Data to support meaningful eradication performance measures are still rare despite such requirements. It can take several decades to achieve eradication since seed banks and other factors often complicate invasive plant eradication efforts. Since eradication of all sites is often preceded by the gradual elimination of some infestations, evaluating trends in site status (whether above-ground plants are present or absent) and site population size (based on complete censuses) may help biosecurity staff to evaluate progress, improve eradication efforts and communicate their successes. These performance measures are illustrated using a 7-year dataset from Raoul Island.

Keywords: eradication, performance measures, Raoul Island, presence/ absence data, complete censuses.
\end{abstract}

\section{INTRODUCTION}

Structural reforms in New Zealand during the late 1980s led to the enshrinement of "new public management" and its emphasis on management objectives and performance measures (Norman 2003). A case in point is the Biosecurity Act 1993, which requires annual operational plans and reports (section 85) and "means for measuring the extent to which the objectives of the strategy are being achieved" (section 76(q)). Since the Act provides little guidance beyond these general requirements, regional council staff have experimented with different reporting methods (Hix et al. 1996; Ward 1996), commissioned several reports exploring various alternatives (BGGG 1994, 1998; Partridge et al. 2002), and included performance measures in every regional pest management strategy (e.g. ARC 2002). Regional councils have targeted 69 different invasive plant taxa for regional or subregional eradication under the Act's provisions (P. Holloran, unpubl. data).

Other agencies are also interested in developing effective pest management performance measures, but have made relatively little progress. In New Zealand, these include the Ministry of Agriculture and Forestry (J. Shelley, pers. comm.) and the Department of Conservation (Lee et al. 2005; E. Wright, pers. comm.). In Australia, the New South Wales Noxious Weeds Advisory Committee sought to develop meaningful performance measures for use in improving evaluation of weed management grants disbursed to local noxious weed authorities (Butt et al. 2004), but that project never got beyond a literature review (Butt 2004; L. Butt, pers. comm.).

To date, most invasive plant performance measures tend to report outputs rather than outcomes. Hix et al. (1996) described several such measures: inspection of all known nassella tussock sites at least twice per year, recording all known nassella tussock sites using GPS, and preparing data sheets on number of nassella tussock plants removed (Hix 
et al. 1996). These measures may be reported as qualitative measures lacking specificity (all sites have been visited twice; ORC 1998) or as quantitative measures (19 mature and 3,668 seedling tussocks removed; ORC 1998). When presented in this fashion, highly aggregated and without further analysis, even quantitative measures such as these are little more than indicators of "busyness" that provide little information about program effectiveness (Butt et al. 2004).

When the objective is eradication, assessing program performance can be particularly challenging. There are uncertainties associated with the three conditions necessary to achieve eradication: ability to detect all individuals, technological means to control all individuals, and being able to do so prior to reproduction (P. Williams, pers. comm.). Detecting every individual is difficult for at least ten different reasons, including environmental conditions, searcher ability and ecological features of the target species (Cacho et al. 2004; Panetta \& Timmins 2004). These factors, particularly the seed bank, can increase the cost and duration of eradication efforts (Cunningham et al. 2003; Panetta 2004). Since success in eradication depends on the species being absent from a region, plants emerging from a long-lived seed bank may cause the species to be present for many years. This may be true even under otherwise perfect conditions (e.g. all individuals detected without error and control techniques that are $100 \%$ effective prior to reproduction).

This article presents eradication performance measures that rely on the fact that the eradication of all sites is often preceded by the gradual elimination of some infestations. These measures may enable managers to determine two things: (1) whether progress, however slow, is being made towards eventual eradication and (2) to what extent the three conditions mentioned previously are being met annually. Unlike many monitoring schemes, these measures do not have complicated data requirements. They require only that every known site be assessed annually for the presence or absence of the target species (or better still, complete censuses of the number of individuals in age classes). When combined with information on new sites discovered during surveillance activities (e.g. searches outside the boundaries of known infestations), these data will indicate whether progress is being made. The reliability of the measures does not depend on perfect adherence to best management practice since the measures, being repeated annually, provide some indication of the extent of deviation from these practices. The measures are illustrated using a 7-year dataset from the eradication efforts of the New Zealand Department of Conservation (DOC) on Raoul Island that targets seven species across more than 3,400 sites.

\section{METHODS}

Details about Raoul Island and the DOC eradication effort can be found in West (1996, 2002). Raoul Island is located at $29^{\circ} 15^{\prime} \mathrm{S}$ and $177^{\circ} 55^{\prime} \mathrm{W}$, approximately 1000 $\mathrm{km}$ northeast of New Zealand. At 2943 ha, it is the largest island in the Kermadec Group. The island is divided into 13 blocks that cover approximately $25 \%$ of the island's area and delimit the area in which target plants are known to be present. These blocks are in turn subdivided into 1 to 30 block plots that range in size from 0.01 ha to 54 ha. Active plots (those with known infestations) are meant to be grid searched at least twice annually. Grid searching involves a team of weed workers walking in parallel lines 6-10 $\mathrm{m}$ apart through a block plot. Individual sites are marked with flagging tape. All detected individuals of target species are controlled using appropriate methods. Seven main species are targeted for eradication: Mysore thorn (Caesalpinia decapetala), African olive (Olea europaea), black passionfruit (Passiflora edulis), purple guava (Psidium cattleianum), yellow guava (Psidium guajava), peach (Prunus persica) and Brazilian buttercup (Senna septemtrionalis).

An Access database implemented in 1997 contains the date and number of individuals (separated by age class) for every visit to a site. For 1998-2004, there are more than 45,000 individual site records. Data entry by weed workers on the island seldom required more than 20-30 minutes/day (M. Ambrose, pers. comm.). Although DOC manages the data 
in a database, it is essentially a spreadsheet containing 6 columns (species/infestation/ seedling population size/adolescent pop. size/mature pop. size/date).

The entire dataset was exported into $\mathrm{R}$, an open-source statistical programming environment that is more or less equivalent to S-Plus (Venables \& Ripley 2002). Short programs were written in $\mathrm{R}$ to convert the population size data into presence/absence data and generate the graphs and tables shown below for each of the seven main target species.

Sites with plants above-ground at any point during a given year were classed as "Active." Sites with no plants visible above-ground during a given year were classed as under "Surveillance", although sites were not marked Surveillance until a second year without above-ground plants. This approach was first used to track progress towards eradication of Class A noxious plant species (Randall 1996; Champion \& Clayton 2003).

\section{RESULTS}

The most compelling eradication performance measure is a stacked bar chart tracking changes in site status over time (Fig. 1). Figure 1 has several advantages. Firstly, the trends that would indicate an effective eradication program are clear. The proportion of sites under Surveillance should keep increasing and the total number of sites should level out at some point. The total number of sites will decrease only if there are missing or unreported data. Secondly, straightforward figures such as these can be presented in combination (e.g. 9 per page) and the reader can move quickly from figure to figure to spot anomalies in the pattern (Tufte 2001).

This site designation system has been adopted by some regional councils for use in their annual reports (e.g. ARC 2004), but they aggregate the data across many species rather than presenting figures for each species. Table 1 illustrates an alternative. Data for individual species are presented along with an aggregated mean across species. The disadvantage of this presentation is that the number of sites is not shown.

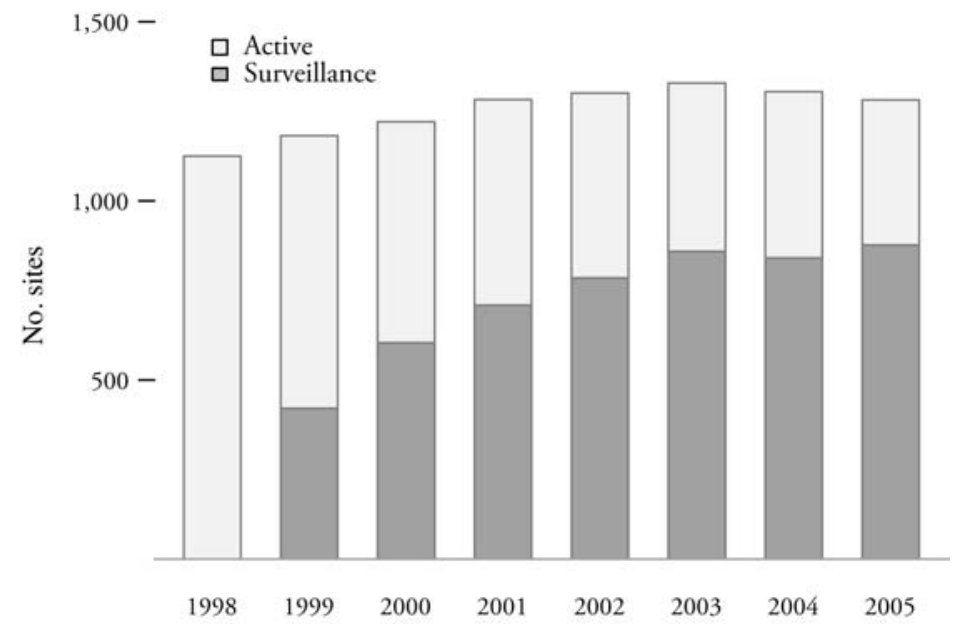

FIGURE 1: Total number of sites that are or have been infested with Brazilian buttercup (Senna septemtrionalis) on Raoul Island during 1998-2005. Infestation status is indicated as Active (total population for the infestation $>0$ in a given year) or Surveillance (total population $=0$ for at least two years). 
TABLE 1: Percentage of all sites that are eradicated for seven weed species on Raoul Island. The last column on the right shows the \% change in the percentage of eradicated sites from 2002-2003 to 2003-2004.

\begin{tabular}{lccccccc}
\hline & $1998-$ & $1999-$ & $2000-$ & $2001-$ & $2002-$ & $2003-$ & $\begin{array}{c}\% \text { change } \\
\text { over last } \\
\text { year }\end{array}$ \\
Species & 1999 & 2000 & 2001 & 2002 & 2003 & 2004 & Caesalpinia decapetala \\
\hline Olea europaea & 40 & 51 & 59 & 66 & 70 & 71 & 1 \\
Passiflora edulis & 25 & 85 & 84 & 85 & 86 & 89 & 3 \\
Psidium cattleianum & 64 & 89 & 77 & 61 & 69 & 71 & 3 \\
Psidium guajava & 54 & 77 & 85 & 79 & 71 & 81 & 14 \\
Prunus persica & 18 & 40 & 44 & 46 & 45 & 43 & -4 \\
Senna septemtrionalis & 36 & 49 & 55 & 60 & 65 & 64 & -2 \\
\hline \multicolumn{1}{c}{ Raoul Island mean } & 44 & 63 & 66 & 68 & 69 & 71 & 3 \\
\hline
\end{tabular}

Tracking the status of individual sites over time provides additional insights into the progress of eradication efforts (Table 2). In the case of Brazilian buttercup, newly eradicated sites continue to outnumber relapsed sites, which are sites that became Active again after being marked Surveillance. Table 2 also indicates that the number of new sites for Brazilian buttercup encountered every year is declining. The number of new sites may take some time to reach zero and remain there. Large-scale disturbance events may occasionally trigger germination events that initiate new sites of Brazilian buttercup, since it was widely distributed prior to eradication efforts. Achieving a low rate of new site discovery is essential to eradication success (Panetta \& Lawes 2005).

TABLE 2: The number of new sites, sites that are still active, relapsed sites and newly eradicated sites for Brazilian buttercup (Senna septemtrionalis) on Raoul Island.

\begin{tabular}{lcccc}
\hline Year & New sites & Still active & Relapsed & Newly eradicated \\
\hline $1998-1999$ & 58 & 703 & 0 & 421 \\
$1999-2000$ & 39 & 556 & 22 & 205 \\
$2000-2001$ & 62 & 463 & 49 & 154 \\
$2001-2002$ & 19 & 458 & 39 & 115 \\
$2002-2003$ & 28 & 385 & 57 & 131 \\
$2003-2004$ & 7 & 405 & 52 & 60 \\
\hline
\end{tabular}

Presence/absence data are less useful when either the sites are very large or when seedlings emerge from a long-lived seed bank every year. In both cases, nearly every site may be marked Active for many years even when significant progress is being made. In the first scenario, a large plot containing many infestations will remain Active until the final infestation is eradicated. Figure 2 illustrates what happens when the Raoul data for Brazilian buttercup were aggregated into 104 block plots rather than 1,305 sites. In the second scenario, sites that remain Active due to annual seed germination may require supplementary information in order to evaluate eradication performance. Tracking changes in the number of plants removed, or a proxy for vines and other species in which individuals are difficult to count, may help indicate progress in such cases. 


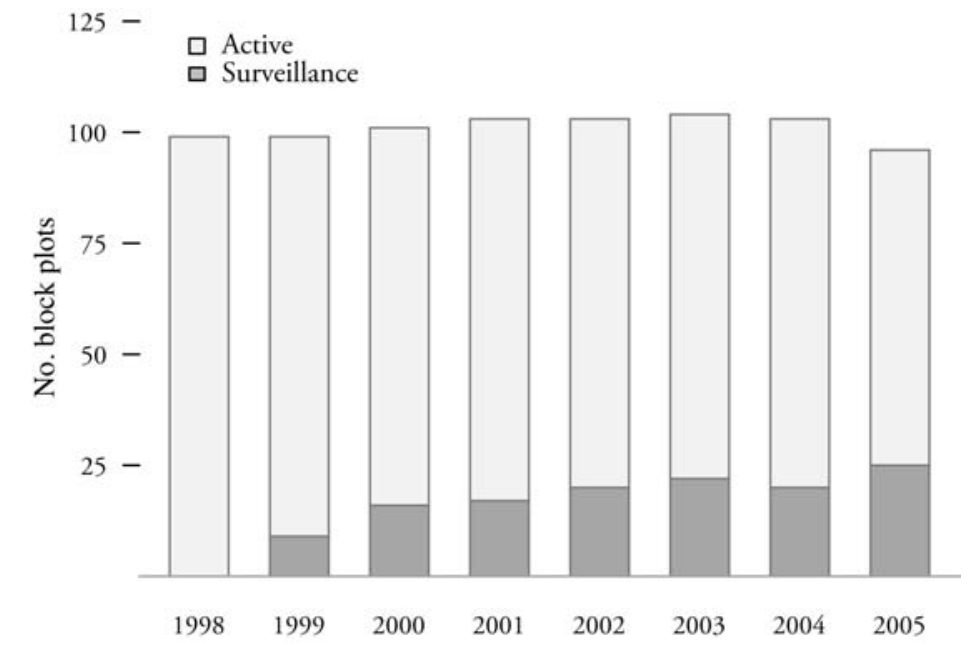

FIGURE 2: Total number of block plots containing Brazilian buttercup (Senna septemtrionalis) on Raoul Island during 1998-2005. These are the same data presented in Figure 1 but aggregated into 104 block plots rather than 1,305 sites.

\section{DISCUSSION}

Presence/absence data and complete censuses can be used in other informative ways, especially when combined with other key variables, such as area, person-hours or spatial location. Such measures include aggregating total population size across all sites (West 2002; Ambrose 2005); output measures such as percentage of sites visited at least twice/year (P. Holloran, unpubl. data); time required to achieve site eradication (Dodd 2004); and bivariate plots of time required to achieve site eradication against infestation size or population size when first detected (Dodd 2004).

But there are at least four challenges in using such data. Firstly, there is considerable subjectivity and variability in how sites are designated. Experienced noxious plants officers may visit the same infestation and arrive at quite different estimates of the number of sites, size of infested area and density, e.g. three small sites of high density or one large site of low density (P. Holloran, unpubl. data). An explicit decision rule for designating sites may reduce subjectivity. Sites that vary across several magnitudes in geographic area or population size can also present problems in interpretation. The number of eliminated sites may mount over time, but if these are mainly outlier infestations with only one or a few plants, then these measures may exaggerate progress towards eliminating core populations. Even so, eliminating small outlier populations can be critically important (Moody \& Mack 1988) and hence worth tracking.

Secondly, some target plants may defy detection even during grid searching, making population censuses less than complete. Marking sites with flagging tape and searching sites more than once per year help mitigate this detection problem on Raoul. The relatively high relapse rate for Brazilian buttercup (Table 2) provides an indication of the extent of the detectability problem, but it could also be a function of its long-lived seed bank (Ambrose 2005) or the algorithm that was used to designate sites under Surveillance (population size $=0$ for two years). Using a different algorithm (population size $=0$ for three years) reduces the number of relapses by $35 \%$ on average but elevates the number of sites that are still active in 2003-2004 by 20\% (P. Holloran, unpubl. data). 
Thirdly, these measures do not directly address surveillance activities, but the number of new sites detected in any given year is a coarse measure of an agency's ability to detect unknown sites that contain species targeted for eradication. Other measures may include the total area searched and changes in its ratio to the infested area (Panetta \& Lawes 2005).

Finally, running $\mathrm{R}$ code may present challenges to practitioners. In the future, the $\mathrm{R}$ code may be translated into Microsoft Excel macros, enabling the user to generate graphs and tables directly from spreadsheets.

Figures and tables like those demonstrated here may help weed workers evaluate whether they are making progress towards a distant goal. Such data also have the virtue of being inexpensive to collect, requiring nothing more than a spreadsheet and 20 minutes/day.

\section{ACKNOWLEDGEMENTS}

Mike Ambrose (Department of Conservation) provided the Raoul Island dataset and insightful comments on an exploratory analysis of that data. Jonathan Boow (Auckland Regional Council), Richard Griffiths (DOC), Dave Kelly (University of Canterbury) and Carol West (DOC) also reviewed that initial exploration and their comments helped sharpen my thinking. Comments by Ian Popay (DOC), Peter Williams (Landcare Research) and Sue Zydenbos (NZPPS) dramatically improved this article. This work was supported by a National Science Foundation Graduate Research Fellowship (US). It is dedicated to Raoul Island weed workers, particularly Mark Kearney, who was killed during the volcanic eruption on 18 March 2006.

\section{REFERENCES}

Ambrose M 2005. Raoul Island weed programme results, 1997 to 2004. Report for Department of Conservation, Auckland Conservancy, Warkworth, New Zealand.

Auckland Regional Council (ARC) 2002. Auckland regional pest management strategy: 2002-2007. Auckland Regional Council, Auckland. 141 pp.

Auckland Regional Council (ARC) 2004. Auckland regional pest management strategy: Annual report, 2003-2004. Auckland Regional Council, Auckland. 27 pp.

Biosecurity Generic Guidelines Group (BGGG) 1994. Regional plant pest management strategies: A guide to their purpose, preparation, and content. Report for Biosecurity Technical Advisory Group, New Zealand. 52 pp.

Biosecurity Generic Guidelines Group (BGGG) 1998. An overview paper: Monitoring regional pest management strategies for performance and review. Report for Biosecurity Technical Advisory Group, New Zealand. 19 pp.

Butt L 2004. Development of performance measures for weed measurement: Literature review. Report for New South Wales Noxious Weeds Advisory Committee. Orange, Australia. $35 \mathrm{pp}$.

Butt L, Carter R, Lisle S, Rawling J 2004. Measuring and evaluating performance in weed management projects. In: Sindel BM, Johnson SB ed. Proceedings of the 14th Australian Weeds Conference. p. 659.

Cacho O, Spring D, Pheloung P, Hester S 2004. Weed search and control: Theory and application. Working Paper Series in Agricultural and Resource Economics No. 2004-11, University of New England, Armidale, New South Wales, Australia. http://www.une.edu.au/economics/publications/gsare/arewp04_11.pdf (accessed 20 May 2006).

Champion PD, Clayton JS 2003. The evaluation and management of aquatic weeds in New Zealand. In: Child LE, Brock JH, Brundu G, Prach K, Pyšek, Wade PM, Williamson $\mathrm{M}$ ed. Plant invasions: Ecological threats and management solutions. Backhuys Publishers, Leiden. Pp. 429-434. 
Cunningham DC, Woldendorp G, Burgess MB, Barry SC 2003. Prioritising sleeper weeds for eradication: Selection of species based on potential impacts on agriculture and feasibility of eradication. Bureau of Rural Sciences, Canberra, Australia. 24 pp.

Dodd J 2004. Kochia (Bassia scoparia (L.) A.J.Scott) eradication in Western Australia: A review. In: Sindel BM, Johnson SB ed. Proceedings of the 14th Australian Weeds Conference. Pp. 496-499.

Hix SJ, Donaldson J, Williams V 1996. Operational plans - a regional council view. Proceedings of the Pest Summit '95, Dunedin, New Zealand. Royal Society of New Zealand, Miscellaneous Series 31. Wellington, New Zealand. Pp. 91-94.

Lee W, McGlone M, Wright E 2005. Biodiversity inventory and monitoring: A review of national and international systems and a proposed framework for future biodiversity monitoring by the Department of Conservation. Landcare Research report for Department of Conservation, Wellington, New Zealand. 213 pp.

Moody ME, Mack RN 1988. Controlling the spread of plant invasions: The importance of nascent foci. Journal of Applied Ecology 25:1009-1021.

Norman R 2003. Obedient servants? Management freedoms and accountabilities in the New Zealand public sector. Victoria University Press, Wellington. 256 pp.

Otago Regional Council (ORC) 1998. Annual report: 1997-1998. Otago Regional Council, Dunedin.

Panetta FD 2004. Seed banks: the bane of the weed eradicator. In: Sindel BM, Johnson SB ed. Proceedings of the 14th Australian Weeds Conference. Pp. 523-526.

Panetta FD, Lawes R 2005. Evaluation of weed eradication programs: the delimitation of extent. Diversity and Distributions 11:435-442.

Panetta FD, Timmins SM 2004. Evaluating the feasibility of eradication for terrestrial weed incursions. Plant Protection Quarterly 19:5-11.

Partridge TR, Whaley KJ, Hunter GG 2002. Pest plant control monitoring techniques for regional and district councils. Part 1: Monitoring framework. Landcare Research report for Biosecurity Managers Group, c/- Environment Canterbury, Christchurch. $57 \mathrm{pp}$.

Randall JL 1996. National pest management strategy for noxious plants. Proceedings of the Pest Summit '95, Dunedin, New Zealand. Royal Society of New Zealand, Miscellaneous Series 31. Wellington, New Zealand. Pp. 53-59.

Tufte ER 2001. The visual display of quantitative information. 2nd ed. Graphics Press, Cheshire, Connecticut. 197 pp.

Venables WN, Ripley BD 2002. Modern applied statistics with S. 4th ed. SpringerVerlag, New York. 495 pp.

Ward G 1996. Noxious plants control-performance measurement. Proceedings of the Pest Summit '95, Dunedin, New Zealand. Royal Society of New Zealand, Miscellaneous Series 31. Wellington, New Zealand. p. 134.

West CJ 1996. Assessment of the weed control programme on Raoul Island, Kermadec Group. Department of Conservation Science \& Research Series No. 98, Department of Conservation, Wellington, New Zealand. $100 \mathrm{pp}$.

West CJ 2002. Eradication of alien plants on Raoul Island, Kermadec Islands, New Zealand. In: Veitch CR, Clout MN ed. Turning the tide: The eradication of invasive species. IUCN SSC Invasive Species Specialist Group. IUCN, Gland, Switzerland and Cambridge, UK. Pp. 365-373. 